\title{
Case-control study of severe pre-eclampsia of early onset
}

\author{
M P MOORE, C W G REDMAN
}

\begin{abstract}
Twenty four women with severe pre-eclampsia diagnosed before 34 weeks' gestation were compared with 48 randomly selected controls matched for age and parity. Subjects were studied in the puerperium using a questionnaire, clinical examination, and review of case records. A history of infertility, headaches (particularly migraine), pre-eclampsia in a previous pregnancy, or a raised serum $\alpha$-fetoprotein concentration at the time of screening for neural tube defect in the index pregnancy were all identified as significant risk factors in the pre-eclamptic women. Maternal age, a history of chronic hypertension or renal disease, or excessive maternal weight were not significantly associated with pre-eclampsia. Almost all the infants of pre-eclamptic women showed retarded growth: 18 were below the 10th centile and only one weighed more than the 25 th centile. Four babies died.

These observations indicate that pre-eclampsia of early onset may differ from the late onset disease not only in its very high perinatal morbidity and mortality but in its distinctive maternal risk factors.
\end{abstract}

\section{Introduction}

Severe pre-eclampsia occurring early in the third trimester is associated with a high perinatal mortality. ${ }^{12}$ Although such cases form a small proportion of patients with pre-eclampsia, they do present a major challenge in management. The affected women are particularly liable to hypertension in later pregnancies, ${ }^{3}$ suggesting that they may have a higher incidence of underlying chronic hypertension or renal disease. This type of preeclampsia has not been characterised in detail. We have therefore undertaken a case-control study of women who developed severe pre-eclampsia before 34 weeks' gestation.

\section{Subjects and methods}

Twenty four patients presenting with severe pre-eclampsia at or before 34 weeks between November 1980 and December 1981 were studied. In 14 cases the condition was first recognised by the general practitioner, and in the remainder it was detected at hospital based antenatal clinics. To identify the cases the maximum antenatal blood pressure (excluding readings in labour) was compared with either the booking blood pressure measured at or before 20 weeks or, if this was not available, the blood pressure six weeks after delivery. Blood pressures were measured according to routine clinical practice with the patient recumbent using a standard mercury sphygmomanometer. Phases I and IV of the Korotkoff sounds were taken as the systolic and diastolic end points. Patients were selected if they met the following criteria: the systolic and diastolic pressures rose by at least 30 and $15 \mathrm{~mm} \mathrm{Hg}$ respectively, and the maximum antenatal systolic and diastolic readings reached or exceeded 140 and $90 \mathrm{~mm}$

\footnotetext{
Nuffield Department of Obstetrics and Gynaecology, John Radcliffe Hospital, Headington, Oxford OX3 9DU

M P MOORE, MB, FRACP, Medical Research Council of New Zealand overseas research fellow

C W G REDMAN, MB, FRCP, lecturer in obstetric medicine

Correspondence to: Dr C W G Redman.
}

$\mathrm{Hg}$ respectively; in addition, persistent proteinuria was present as defined by a result of $2+$ or more on Albustix, or $1.0 \mathrm{~g}$ or more per litre in a midstream urine sample, or $1.0 \mathrm{~g}$ or more in a 24 hour urine collection. One patient who fitted these diagnostic criteria but who had a phaeochromocytoma was excluded. The study was designed so that patients were identified retrospectively using the range of clinical observations employed in routine clinical practice. No attempt was made to superimpose extra observations-for instance, special blood pressure readings-which would not be immediately comparable with those available in all obstetric units.

Patients were identified before any further assessment took place so that the consequences of assessment could not influence the process of patient selection. All patients were interviewed using a standard questionnaire and examined by one of us (MPM) during the first postpartum week. The questionnaire included questions about vasospastic disorders because our previous observations (unpublished) had suggested that both a history of migraine and Raynaud's phenomenon might be significantly associated with early onset pre-eclampsia. The case notes were also reviewed. Particular attention was paid to the occurrence of a high serum $x$-fetoprotein concentration in the period 16-20 weeks not associated with a neural tube defect. Our previous experience had suggested an unusually high incidence of this abnormality in patients with early onset pre-eclampsia. For each case two randomly selected control subjects were matched for age and parity and studied in an identical manner. Controls were identified by taking the first woman who matched after a random number of days and a random time of the day after delivery of the index patient.

Statistical analyses were by Student's $t$ test, the $\%^{2}$ test, and the Fisher exact test.

\section{Results}

Table I gives the age and parity distribution of the index patients and controls. As expected, the pre-eclamptic women included a high proportion of nulliparas $\left(71^{\prime \prime}\right)$. This contrasted with the total hospital population, of whom $43.7^{\circ}$, were nulliparous. The average age of the pre-eclamptic women ( 26.4 years) was slightly less than the mean for the total hospital population $(27 \cdot 1)$, but when only nulliparous women were considered the mean ages were the same (24.9 and $25 \cdot 1$ years respectively).

The distribution of social class by the Registrar General's classification showed similar patterns in the two groups, except for an unexplained deficit of pre-eclamptic women in social class II. When the social background of the subjects was judged according to a classification of their accommodation (number of bedrooms, ownership, type of building) there was no difference between the two groups. We therefore conclude that, overall, they did not differ in their social characteristics.

Blood pressures at the time of booking were similar in the two groups, whereas, as expected, the maximum blood pressures were greatly increased in the pre-eclamptic women (table I). Blood pressures six weeks after delivery were available in the index patients but not the controls. The means and standard deviations were 124 (13)/ $83(12) \mathrm{mm} \mathrm{Hg}$. In all instances the postnatal blood pressure was lower than the maximum antenatal readings. In 22 cases this was by a decrement of at least $30 / 15 \mathrm{~mm} \mathrm{Hg}$. In two cases the decrements were $38 / 12 \mathrm{~mm} \mathrm{Hg}$ and $22 / 22 \mathrm{~mm} \mathrm{Hg}$. The first of these was a woman with bilateral parenchymal renal disease about whom further details are given below. Twenty two pre-eclamptic women had proteinuria of $2+$ or more on testing with Albustix. Two had only $1+$ proteinuria. One of these, however, had a protein concentration of $1.0 \mathrm{~g} / \mathrm{l}$ in a midstream urine specimen and the other a total excretion of $1.4 \mathrm{~g}$ in a 24 hour urine collection. The 24 hour urinary protein excretion was measured in 18 cases and averaged $4.9 \mathrm{~g} / 24 \mathrm{~h}(1 \cdot 0-11 \cdot 1 \mathrm{~g} / 24 \mathrm{~h})$. The remaining six women were delivered within 24 hours of admission, four of them within six hours of admission. In three a midstream urine sample was taken in which proteinuria of $1.0 \mathrm{~g} / 1$ or more was measured in the absence of other urinary abnormalities. The other three patients were transferred from other hospitals, where persistent 
proteinuria had been documented. In each case this was confirmed by testing in the ward on admission, but more precise measurements were not obtained in the brief interval before delivery. In these three cases the detection of proteinuria rested solely on repeated positive ward test results. Two of the controls had $1+$ proteinuria on at least one occasion before 34 weeks but neither had persistent proteinuria. One control woman developed proteinuric pre-eclampsia by the study criteria after 34 weeks; two other controls had pre-eclamptic hypertension but no proteinuria. The plasma urate concentration was measured at booking in 33 control and 13 pre-eclamptic women, and the mean values were closely similar (table I). The mean maximum urate concentration was greatly increased in the pre-eclamptic group but remained normal in the controls (table I).

The pre-eclamptic women were slightly shorter than the controls and weighed proportionately less at booking. Examination after delivery, however, showed that they were a little more obese as judged by skinfold thicknesses and arm circumferences, but none of the differences was significant (table II). Another index of obesitybody mass index (weight $(\mathrm{kg}) /$ height $(\mathrm{m})^{2}$ )-was calculated using the weight at booking. ${ }^{4}$ The mean values in the two groups were similar (table II). The booking blood pressures did not suggest that the preeclamptic group included a significant number of women with chronic hypertension. This observation was strengthened in two ways. Firstly, the pre-eclamptic women did not have a history of hypertension more frequently, although slightly more were known to have had hypertension while taking oral contraceptives (table III). Secondly, the family histories of hypertension and other arterial disease did not differ. Nine pre-eclamptic women $\left(38^{\circ}\right)$ compared with 17 controls

TABLE I-Age, parity, blood pressure, and plasma urate concentrations in preeclamptic and normal women

\begin{tabular}{|c|c|c|}
\hline & $\begin{array}{l}\text { Control } \\
(n=48)\end{array}$ & $\begin{array}{l}\text { Pre-eclampsia } \\
\quad(n=24)\end{array}$ \\
\hline \multirow{5}{*}{$\begin{array}{l}\text { Mean age, in years (range) } \\
0 \\
\text { Parity }\left\{\begin{array}{c}1 \\
2 \\
2\end{array}\right. \\
\text { Mean blood pressure at booking, } \\
\text { in mm Hg (1 SD)t } \\
\text { Mean maximum blood pressure } \\
\text { in mm Hg (1 SD) } \\
\text { Mean plasma urate at booking, } \\
\text { in mmol/1 (1 SD) } \\
\text { Mean maximum plasma urate, } \\
\text { in mmol/1 (1 SD) }\end{array}$} & $\begin{array}{r}26 \cdot 3(16-37) \\
34 \\
8 \\
4 \\
2\end{array}$ & $\begin{array}{c}26 \cdot 4(17-37) \\
17 \\
4 \\
2 \\
1\end{array}$ \\
\hline & $121(11 \cdot 5) / 70(9 \cdot 3)$ & $121(13 \cdot 8) / 73(10 \cdot 9)$ \\
\hline & $129(10 \cdot 8) / 78(8 \cdot 1)$ & $179(17 \cdot 3)^{* *} / 117(11 \cdot 2)^{* *}$ \\
\hline & $0.20(0.04)(n=33)$ & $0.23(0.06)(n=13)$ \\
\hline & $0.26(0.06)(n=33)$ & $0.42(0.08)^{*}(n=21)$ \\
\hline
\end{tabular}

*p $0.01, * * \mathrm{p}<0.001$ compared with controls. Includes one blond pressure reading taken after 20 weeks' gestation in each group.
Conversion: SI to traditional units-Urate: $1 \mathrm{mmol} / 1 \approx 16.8 \mathrm{mg} / 100 \mathrm{ml}$.

TABLE II-Body build of pre-eclamptic and normal women. Values are means (1 SI) in parentheses)

\begin{tabular}{|c|c|c|}
\hline & $\begin{array}{l}\text { Control } \\
(n=48)\end{array}$ & $\begin{array}{l}\text { Pre-eclampsia } \\
\quad(n=24)\end{array}$ \\
\hline $\begin{array}{l}\text { Height }(\mathrm{cm}) \\
\text { Wecks of gestation at first visit } \\
\text { Weight at first visit (kg) } \\
\text { Body mass index }{ }^{*}(\mathrm{~mm})+ \\
\text { Skinfold thickness }(\mathrm{mm}){ }^{+} \\
\text {Arm circumferences }(\mathrm{cm})_{+}^{+}\end{array}$ & $\begin{array}{l}161.6(5.7) \\
13.3(5.3) \\
61.1(8.8) \\
23.4(3.5) \\
70.3(18.6) \\
50.7(4.6)\end{array}$ & $\begin{array}{l}159.3(9.5) \\
12.9(5.1) \\
59 \cdot 7(6.3) \\
23.5(2.3) \\
79.2(21.3) \\
52.3(4.9)\end{array}$ \\
\hline
\end{tabular}

"Body mass index calculated as weight (kg)/height $(\mathrm{m})^{2}$.

tSum of triceps, subscapular, and suprailiac skinfolds measured after delivery.
\$ Sum of both upper arm circumstances measured after delivery.

TABLE III-Previous medical histories in the two groups of women (percentages in parentheses)

\begin{tabular}{lrr}
\hline & $\begin{array}{r}\text { Control } \\
(\mathrm{n}=48)\end{array}$ & $\begin{array}{r}\text { Pre-eclampsia } \\
(\mathrm{n}=24)\end{array}$ \\
\hline One or more urinary infections before pregnancy & $11(23)$ & $6(25)$ \\
Renal disease & $4(8)$ & $3(13)$ \\
History of hypertension & $2(4)$ & 0 \\
Use of oral contraceptives & $39(81)$ & $19(79)$ \\
Hypertension on oral contraceptivest & $3 / 33(9)$ & $3 / 14(21)$ \\
Headaches & $8(17)$ & $13(54) *$ \\
Raynaud's phenomenon & $2(4)$ & $3(15)$ \\
Allergies & $15(31)$ & $3(13)$
\end{tabular}

* $\mathrm{p}<0.001$

tDenominators are numbers of women who both took oral contraceptives and had their blond pressures checked while taking them
TABLE IV-Reproductive history of pre-eclamptic and normal women (percentages in parentheses)

\begin{tabular}{lrr}
\hline & $\begin{array}{c}\text { Control } \\
(\mathrm{n}=48)\end{array}$ & $\begin{array}{c}\text { Pre-eclampsia } \\
(\mathrm{n}=24)\end{array}$ \\
\hline Primigravid & $26(54)$ & $11(46)$ \\
Infertility & $3(6)$ & $6(25) * *$ \\
Onc or more abortionst & $13(27)$ & $8(33) \ddagger$ \\
Previous viable nregnancies & $14(29)$ & $7(29)$ \\
Pre-cclamptic in previous pregnancy & $1(2)$ & $4(17)^{*}$ \\
\hline
\end{tabular}

$* \mathrm{p}=0.048, * * \mathrm{p}=0.033$ compared with controls.

+Spontaneous or induced.
† Includes one patient with two ectopic pregnancies.

TABLE v-Cigarette smoking and other complications of pregnancy (percentages in parentheses)

\begin{tabular}{lcc}
\hline & $\begin{array}{c}\text { Control } \\
(\mathrm{n}=48)\end{array}$ & $\begin{array}{c}\text { Pre-eclamptic } \\
(\mathrm{n}=24)\end{array}$ \\
\hline Smoking at conception & $18(38)$ & $6(25)$ \\
Smoking before delivery & $13(27)$ & $5(21)$ \\
Urinary infection & $3(6)$ & $4(17)$ \\
High $\alpha$-fetoprotein value & 0 & $3(13)^{*}$ \\
\hline
\end{tabular}

* $p=0.034$ compared with controls.

$(35$.$) gave a family history of hypertension in parents or siblings.$ Similarly, coronary artery and cerebrovascular disease were equally common in families of both groups.

Tables III and IV summarise the results of other questions relating to health and obstetric history. There was no clear evidence that the pre-eclamptic women had more renal disease or were particularly susceptible to urinary infections. The index patients but not the controls had a further assessment of renal state including renal function measurements six weeks after delivery. An intravenous pyelogram more than three months after delivery was normal in all but three women. In one there was a minor unilateral small cyst, in the second there was a unilateral small scarred kidney, and in the third there were bilateral small scarred kidneys. This last patient was the only one who had renal impairment when assessed six weeks after delivery as judged by a plasma creatinine concentration exceeding $100 \mu \mathrm{mol} / 1(1.1 \mathrm{mg} / 100 \mathrm{ml})$. She was also the only patient in the preeclamptic group to have more than $1.0 \mathrm{~g}$ of protein persisting in a 24 hour urine sample. Otherwise urinary protein excretion was undetectable, or in two instances persisted at $0.4 \mathrm{~g} / 24 \mathrm{~h}$. Overall two cases of unequivocal parenchymal renal disease were detected. Given that no cases would have been detected in the controls had they been similarly investigated, the difference would not be significant $(p>0 \cdot 1)$.

Headaches occurring before pregnancy were significantly more common in the pre-eclamptic group. They were particularly migrainous in type: eight pre-eclamptic women $(33 \%)$ compared with three of the control ( $6 \%$ ) described headaches accompanied by nausea, vomiting, or visual disturbances $(p<0.01)$. The mean booking blood pressures of pre-eclamptic women with and without a history of headache $(120.5$ (1 SD 13.9)/72.2 (9.8) $\mathrm{mm} \mathrm{Hg}$, and $122.5(14.3) / 72.7$ $(12 \cdot 7) \mathrm{mm} \mathrm{Hg}$ respectively) were similar, suggesting that a tendency to headache was not associated with pre-existing hypertension. Raynaud's phenomenon-like migraine, a disorder of the control of peripheral arterial tone-was also more common in pre-eclamptic women but the difference was not significant $(p>0 \cdot 15)$.

Significantly more pre-eclamptic women gave a history of infertility (table IV). Infertility was deemed to be present if the patient had attended an infertility clinicat any time. Infertility was primarily caused by a failure to conceive rather than a higher incidence of spontaneous abortions. More than half the parous women had had pre-eclampsia before. Of these, the disorder was less severe in the index pregnancy in two cases and more or as severe in the other two. In contrast, only one out of 14 of the parous women in the control group had had preeclampsia before (table IV). Five pre-eclamptic women $(21 \%)$ and 11 control subjects $(23 \%)$ reported a family history of hypertension in pregnancy in mother or dister.

Table $\mathrm{V}$ summarises factors relating to the index pregnancy. While cigarette smoking was less prevalent and urinary infections more common in the pre-eclamptic group, the differences were not statistically significant. There was an excess of index patients who had been referred for amniocentesis because of a raised serum $\alpha$-fetoprotein concentration in the second trimester. Concentrations were $2.59,3.77$, and 4.27 when expressed as multiples of the median for 
gestational age. In all three cases a neural tube defect was excluded by a normal concentration of $x$-fetoprotein in the amniotic fluid. The women had singleton pregnancies and the gestational maturity at the time of sampling (16-18 weeks) was checked by ultrasound measurement of fetal size.

Table VI shows the caesarean section rate and fetal outcome. Of the 20 caesarean sections in the pre-eclamptic group, 17 were performed for fetal or maternal compromise before labour. One of the pre-eclamptic patients had had several eclamptic fits before transfer to Oxford, where labour was induced at 26 weeks' gestation for maternal reasons. This accounted for one of the intrauterine deaths. The other was associated with a placental abruption at 25 weeks' gestation. The two neonatal deaths were associated with extreme prematurity, the infants being delivered at 28 and 29 weeks, weighing 600 and $700 \mathrm{~g}$ respectively. Retarded growth was a feature of nearly all the pre-eclamptic cases. Only one infant was above the 25 th centile for gestation and sex in the pre-eclamptic group, while 18 were below the 10th centile (table VI).

TABLE VI-Mode of delivery and perinatal outcome (percentages in parentheses)

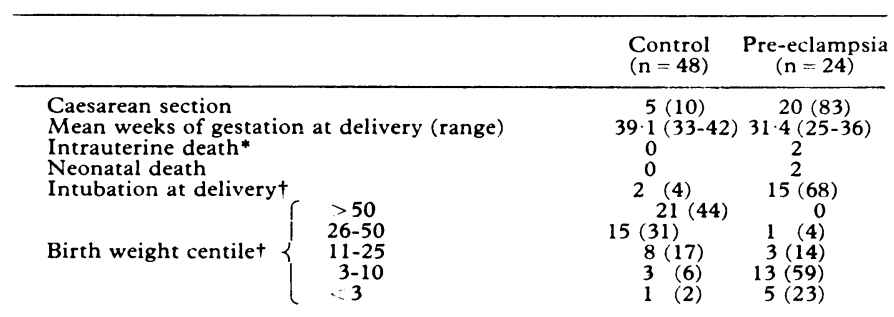

"Includes all losses after 24 weeks' gestation.

tTwo cases of intrauterine death at 25 and 26 weeks excluded from pre-eclamptic group (fetuses weighed 505 and $395 \mathrm{~g}$ respectively). Percentages in parentheses therefore calculated as proportion of remaining 22 patients.

\section{Discussion}

These data do not allow the incidence of severe early onset pre-eclampsia to be calculated because hospital admissions cannot be related to a single population base. During the study a total of 6746 patients were delivered in Oxford. The hospital incidence of the disorder was therefore $0.36^{\circ}$. Five of the patients were transferred from other hospitals, however, so that the true incidence is probably of the order of $0.25 \%$.

One of our main objects was to determine whether early onset pre-eclampsia was associated with a high incidence of medical problems. Within the limits of the methods used this was not shown. In particular, neither chronic hypertension nor renal disease seems to be a significant identifiable predisposing factor. This does not exclude the possibility that in later life problems which were not evident at the time of the study will emerge.

We cannot specify to what extent the other features of the pre-eclamptic group reflected the condition in general rather than its atypical early onset. In assessing the data two general factors need to be considered. Firstly, the small numbers allow only major differences from the control group to be detected. Secondly, in other studies of pre-eclampsia neither such stringent diagnostic criteria nor case-control methods have been used.

It is widely believed that pre-eclampsia is associated with obesity. ${ }^{5}$ Although the postnatal measurements of arm circumference and skinfold thickness were apparently consistent with this, the differences were not significant. Moreover, persisting fluid retention in the pre-eclamptic group may have biased the measurements in this direction. The index of weight for height, ${ }^{4}$ calculated on the weight at booking showed no differences. Overall obesity therefore appears not to be a significant factor, which agrees with Lowe. ${ }^{6}$ It is theoretically possible but not likely that the persisting oedema could have biased the skinfold measurements, so that a significant lack of subcutaneous fat in the pre-eclamptic women would be missed. The tendency for pre-eclamptic women to be shorter has been reported before. ${ }^{7}$
There was a striking increase in the incidence of headaches preceding the index pregnancies, and most of them were migrainous. An association between migraine and pre-eclampsia has been suggested ${ }^{9}$ but was not confirmed in a later study. ${ }^{10}$ Retrospective assessment of headaches may be biased by the patient's expectation of symptoms in relation to a known diagnosis of hypertension. This can be excluded only by a prospective study. Our subjects, however, were particularly asked to report only those headaches which preceded the pregnancy-that is, excluding the period when the patients knew that high blood pressure was present. The association was strengthened when specific migrainous symptoms were considered, which unlike headaches patients do not particularly relate to hypertension. We therefore believe that this is a real association. Migraines are common in women of childbearing age" and are not associated with higher blood pressures than average. ".2 Headaches, however, are also recognised as a symptom of severe hypertension. ${ }^{13}$ These headaches are distinct from migraines, typically being present on waking and occipital in distribution. ${ }^{14}$ These earlier observations, combined with our own, suggest that the association of migraines and pre-eclampsia is not dependent on hypertension but on some other mechanism. Abnormal vascular reactivity is a feature of pre-eclampsia ${ }^{15}$ and is also observed in migrainous subjects between attacks, ${ }^{16} 1^{17}$ and this may provide the linking factor. Both conditions are also characterised by abnormalities of platelet behaviour. Platelets taken from migrainous subjects during a headache free period show higher spontaneous aggregation and adhesion than normal. ${ }^{1 *}$ Increased platelet consumption is an early feature of pre-eclampsia ${ }^{19}$; an intrinsic abnormality of platelets could amplify this, contributing to the severity of the disease.

There was also a threefold increase in the incidence of another vasospastic disorder, Raynaud's phenomenon, in the preeclamptic women, but this was not statistically significant. Migraines and Raynaud's phenomenon are both associated with variant angina but not classical coronary artery disease. ${ }^{20}$ The possible association of Raynaud's phenomenon with preeclampsia is therefore of some interest, perhaps indicating that early onset pre-eclampsia belongs to this group of conditions, which seem to share an underlying abnormality of control of arterial tone. ${ }^{21}$

A significant feature of the pre-eclamptic group was the high incidence of previous infertility. This has not been observed in relation to pre-eclampsia in general, so that, if real, the association must be specifically with the early onset disease. We had no hypothesis to test against this observation, so that the association will need confirmation in other studies. As expected, the pre-eclamptic group included a significantly higher proportion of primiparous women than did the whole hospital population. After matching for parity no difference was observed in the proportion of women with or without previous non-viable pregnancies. This contrasts with the decrease in pre-eclampsia rates associated with previous abortions noted by MacGillivray. ${ }^{22}$ Of the seven patients with previous viable pregnancies, four had suffered pre-eclampsia and one had shown a rise in blood pressure. This is in keeping with the reported high incidence of recurrent gestational hypertension in women with pre-eclampsia at an early gestation. ${ }^{3}$

Fetal growth retardation was a major feature of the preeclamptic pregnancies, 18 out of 22 infants $(82 \%)$ weighing less than the 10th centile. A similar but less pronounced association has been noted in women with proteinuric pre-eclampsia before 37 weeks, of whom $22 \%$ had infants weighing less than the 10th centile. ${ }^{23}$ Thus the evidence suggests that the earlier the onset the more likely is pre-eclampsia to be associated with fetal growth impairment. Low birth weight has been previously associated with a high maternal serum $\alpha$-fetoprotein concentration at the time of screening for neural tube defects. ${ }^{24}$ The extent to which pre-eclampsia might contribute to this correlation by causing prematurity or fetal growth retardation, or both, has not been analysed. The association of a raised maternal serum $\alpha$-fetoprotein value with early onset pre-eclampsia may 
therefore be a particular aspect of a wider problem. Established pre-eclampsia may also be associated with a high maternal serum $\alpha$-fetoprotein concentration, ${ }^{25}{ }^{26}$ although earlier reports suggested an overall reduction in values. ${ }^{27} 28$

The small number of cases available for study limits interpretation of the results. It appears that pre-existing hypertension is not a predisposing factor in the development of severe early onset pre-eclampsia. The risk factors that we have been able to identify are: a previous history of pre-eclampsia, a history of infertility, a history of headaches-particularly migraines-and a raised serum $\alpha$-fetoprotein concentration at the time of screening for neural tube defects.

\section{References}

${ }^{1}$ Butler NR, Bonham DG. Perinatal mortality. Edinburgh: E and $S$ Livingstone Ltd, 1963:86-100.

2 Chamberlain G, Philipp E, Howlett B, Masters K. British births. London William Heinemann Medical Books Ltd, 1970:80-107.

3 Chesley LC. Hypertensive disorders in pregnancy. New York: AppletonCentury-Crofts, 1978:427.

4 Billewicz WZ, Kemsley WFF, Thomson AM. Indices of adiposity. British Fournal of Preventive and Social Medicine 1962;16:183-8.

${ }^{6}$ Stewart A, Hewitt D. Toxaemia of pregnancy and obesity. Fournal of Obstetrics and Gynaecology of the British Empire 1960;67:812-8.

- Lowe CR. Toxaemia and pre-pregnancy weight. Fournal of Obstetrics and Gynaecology of the British Commonwealth $1961 ; 68: 622-7$.

${ }^{7}$ Butler NR, Alberman ED. Perinatal problems. Edinburgh: E and S Livingstone Ltd, 1969:36-9.

${ }^{8}$ Baird D. Epidemiological aspects of hypertensive pregnancy. Clin Obstet Gynaecol 1977;4:531-48.

'Rotton WN, Sachtleben MR, Friedman EA. Migraine and eclampsia. Obstet Gynecol 1959;14:322-30.

10 Wainscott G, Sullivan FM, Volans GN, Wilkinson M. The outcome of pregnancy in women suffering from migraine. Postgrad Med $\mathcal{F}$ 1978;54: 98-102.

"Walters WE, O'Connor PJ. Epidemiology of headache and migraine in women. $\mathcal{F}$ Neurol Neurosurg Psychiatry 1971 ; 34:148-53.
12 Walters WE. Headache and blood pressures in the community. $\mathrm{Br} \mathrm{Med} \mathfrak{f}$ $1971 ; \mathrm{i}: 142-3$

${ }^{13}$ Bulpitt CJ, Dollery CT, Carne S. Change in symptoms of hypertensive patients after referral to hospital clinic. Br Heart $\mathcal{f}$ 1976;38:121-8.

${ }^{14}$ Pickering GW. High blood pressure. London: Churchill, 1968:324.

${ }^{15}$ Gant NF, Daley GL, Chand S, Whalley PJ, Macdonald PC. A study of angiotensin II pressor response throughout primigravid pregnancy. $f$ Clin Invest $1973 ; 52: 2682-9$

${ }^{16}$ Franchi G, Anselmi B, Michelacci S. Change in serotonin and catecholamines vascular reactivity during migraine attack. Res Clin Stud Headache $1972 ; 3: 304-9$.

17 Appenzeller O, Davison K, Marshall J. Reflex vasomotor abnormalities in the hands of migrainous subjects. $\mathcal{F}$ Neurol Neurosurg Psychiatry 1963; 26 : $447-50$.

${ }^{18}$ Hanington E, Jones RJ, Amess JAL, Wachowicz B. Migraine: a platelet disorder. Lancet 1981 ;ii:720-3.

19 Redman CWG, Bonnar J, Beilin LJ. Early platelet consumption in preeclampsia. $\mathrm{Br} \mathrm{Med} \mathcal{F}$ 1978; :467-9.

${ }^{20}$ Miller D, Waters DD, Warnica W, Szlachcic J, Kreeft J, Theroux P. Is variant angina the coronary manifestation of a generalised vasopastic disorder? $N$ Engl f Med 1981 ;304:763-6.

${ }^{21}$ Coffman JD, Cohen RA. Vasospasm-ubiquitous? N Engl $\mathcal{F}$ Med 1981 ; 304:780-2.

${ }^{22}$ MacGillivray I. Some observations on the incidence of pre-eclampsia. Fournal of Obstetrics and Gynaecology of the British Empire 1958;65:536-

${ }^{23}$ Long PA, Abell DA, Beischer NA. Fetal growth retardation and preeclampsia. Br F Obstet Gynaecol 1980;87:13-8.

24 Wald NJ, Cuckle HS, Boreham J, Turnbull AC. Maternal serum alphafetoprotein and low birthweight. Br F Obstet Gynecol 1980;87:860-3.

${ }^{25}$ Clayton-Hopkins JA, Oslen PN, Blake AP. Maternal serum alphafetoprotein levels in the pregnancy complicated by hypertension. Prenatal Diagnosis $1982 ; 2: 47-54$.

${ }^{26}$ Kahlil FK, Bonnet M, Guibaud S, Combet A, Thoulon JM, Dumont M Alpha-fetoprotein levels in placenta, maternal and cord blood in norma and pathologic pregnancy. Obstet Gynecol 1979;54:117-9.

${ }^{27}$ Rodeck CH, Campbell S, Biswas G. Maternal plasma alpha-fetoprotein in normal and complicated pregnancies. Br $\mathcal{F}$ Obstet Gynaecol 1979;83 24-32.

${ }^{28}$ Garoff L, Seppälä M. Toxemia of pregnancy: assessment of fetal distress by assaying estriol and circulating human placental lactogen and alphafetoprotein levels. Am $\mathcal{F}$ Obstet Gynecol 1976;126:1027-33.

(Accepted 24 May 1983)

\section{SHORT REPORTS}

\section{Rebreathing during use of the Air-Viva resuscitation bag: a hazard}

Self inflating resuscitator bags used for ventilatory support usually contain a valve arrangement to separate inspired from expired gases. On inspection the valve of the Air-Viva bag appeared inadequate to prevent the rebreathing of expired gas. We decided to test this hypothesis and also to test other readily available bags.

\section{Methods and results}

The following resuscitation bags were examined: Airox, Air-Viva, AirViva 2, Ambu Compact, Ambu Universal, Laerdal, Ohio, PMR, PMR 2, Penlon, Robertshaw, Sabre/Sussex, and Vitalograph. The bags were tested with an International Standards Organisation lung of standard specifications (compliance $0.021 / \mathrm{cm} \mathrm{H}_{2} \mathrm{O}$ and resistance $20 \mathrm{~cm} \mathrm{H}_{2} \mathrm{O} / 1 / \mathrm{s}$ ); carbon dioxide was introduced into the lung at $200 \mathrm{ml} / \mathrm{min}$ to simulate the patients' carbon dioxide production. The lung was then ventilated with each resuscitator bag. The respiratory flows produced were measured with a pneumotachograph (Hewlett Packard) and the signal integrated to give tidal volume. Carbon dioxide concentrations were measured continuously with a Datex infrared carbon dioxide meter with printer. The gas for this analysis was sampled from the patient port of the resuscitator. The bags were compressed at a fixed rate of $20 \mathrm{breaths} / \mathrm{min}$ for two five minute periods. During the first period the bags were squeezed with one hand to simulate normal use. To test the effect of increased tidal volume two hands were used for the second period. The Air-Viva bag was also tested over a longer period (15 mins) and with supplementary oxygen. Three other Air-Viva bags were picked at random from various departments of the hospital and submitted to the same tests.

When compressed with one hand all the bags produced tidal volumes in the range of $400-650 \mathrm{ml}$; two hands increased the volume range to 500 $800 \mathrm{ml}$. All the bags tested, apart from the Air-Viva, produced satisfactory results at both tidal volumes with zero carbon dioxide during the inspiratory phase (figure). With the Air-Viva, however, the inspired carbon dioxide concentration rose immediately - that is, rebreathing occurred-and after $20-30$ seconds reached a plateau of $2 \%$, which was then maintained throughout the five and 15 minute periods. Increasing the tidal volume did not influence this rise in inspired carbon dioxide. The three other Air-Viva bags tested showed the same pattern. Use of increasing flows of supple-
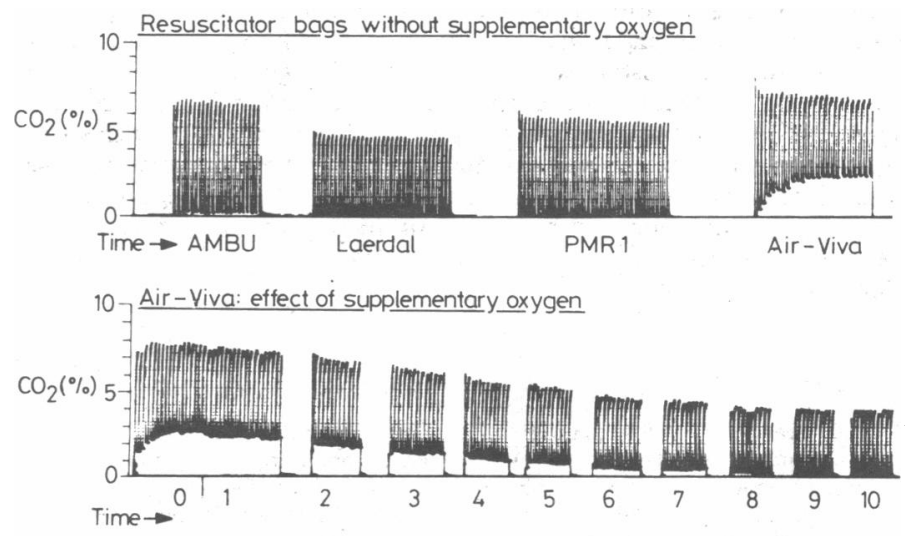

Top: Tidal carbon dioxide traces with Air-Viva and some satisfactory bags. Bottom: Effect of added oxygen on inspired carbon dioxide concentration with Air-Viva, oxygen flows $0-10 \mathrm{l} / \mathrm{min}$. 